\title{
Interventions for improving outcomes in patients with multimorbidity in primary care and community setting: a systematic review
}

Susan M. Smith ${ }^{1 *} \mathbb{D}$, Emma Wallace ${ }^{1}$, Barbara Clyne ${ }^{1}$, Fiona Boland ${ }^{2}$ and Martin Fortin ${ }^{3}$

\begin{abstract}
Background: Multimorbidity, defined as the co-existence of two or more chronic conditions, presents significant challenges to patients, healthcare providers and health systems. Despite this, there is ongoing uncertainty about the most effective ways to manage patients with multimorbidity. This review updated and narrowed the focus of a previous Cochrane review and aimed to determine the effectiveness of interventions designed to improve outcomes in people with multimorbidity in primary care and community settings, compared to usual care.
\end{abstract}

Methods: We searched eight databases and two trials registers up to 9 September 2019. Two review authors independently screened potentially eligible titles and selected studies, extracted data, evaluated study quality and judged the certainty of the evidence (GRADE). Interventions were grouped by their predominant focus into carecoordination/self-management support, self-management support and medicines management. Main outcomes were health-related quality of life (HRQOL) and mental health. Meta-analyses were conducted, where possible, but the synthesis was predominantly narrative.

Results: We included 16 RCTs with 4753 participants, the majority being older adults with at least three conditions. There were eight care-coordination/self-management support studies, four self-management support studies and four medicines management studies. There was little or no evidence of an effect on primary outcomes of HRQOL (MD $0.03,95 \% \mathrm{Cl}-0.01$ to $0.07, P^{2}=39 \%$ ) and mental health or on secondary outcomes with a small number of studies reporting that care coordination may improve patient experience of care and self-management support may improve patient health behaviours. Overall, the certainty of the evidence was graded as low due to significant variation in study participants and interventions.

Conclusions: There are remaining uncertainties about the effectiveness of interventions for people with multimorbidity, despite the growing number of RCTs conducted in this area. Our findings suggest that future research should consider patient experience of care, optimising medicines management and targeted patient health behaviours such as exercise.

\footnotetext{
*Correspondence: susansmith@rcsi.ie

${ }^{1}$ Department of General Practice and HRB Centre for Primary Care

Research, Royal College of Surgeons, 123 St Stephens Green, Dublin 2, Ireland

Full list of author information is available at the end of the article
}

\begin{abstract}
Background
There is now greater recognition of the impact of living with multiple chronic conditions, defined as multimorbidity and of the importance of improving outcomes for individuals affected [1-3]. Individuals with multimorbidity are more likely to die prematurely, be admitted to hospital and have longer hospital stays $[4,5]$. They have poorer quality of life, loss of physical functioning, and are
\end{abstract}


more likely to suffer from psychological stress [6-9]. The negative impact of multimorbidity is higher in the most disadvantaged communities with earlier onset and more complex combinations of mental and physical health conditions $[10,11]$. Medicines management is often complex, resulting in polypharmacy with its attendant risks of drug interactions and adverse drug events [12, 13]. Patients must also attend multiple appointments with different healthcare providers and adhere to lifestyle recommendations. This adds to complexity and can sometimes lead to confusion with multiple treatments and guidance adding to treatment burden for patients [14]. Fragmentation of care is a significant problem for this group, resulting from the involvement of both primary care and multiple specialists who may not be communicating with each other effectively [15]. Clinical guidelines that address multimorbidity and related areas such as polypharmacy have emphasised the need for good quality evidence from primary studies $[13,16]$.

Given the challenge of managing people with multimorbidity, potential interventions are likely to be complex and multifaceted. The previous Cochrane review of interventions for multimorbidity [17] incorporated studies targeting both multimorbidity and comorbidity but as evidence evolves a distinction needs to be made between these two concepts. Interventions for comorbidity studies include specific groups of patients and can be designed to target the index and comorbid conditions, for example diabetes and comorbid depression. On the other hand, interventions for multimorbidity need to have a more generic focus that will work across a broad range of conditions. These distinctions are important in the context of developing and evaluating effective interventions for multimorbidity and considering their generalisability [18]. This systematic review updated and narrowed the focus of a previous Cochrane review and aimed to determine the effectiveness of interventions designed to improve outcomes in people with multimorbidity in primary care and community settings.

\section{Methods}

This systematic review is an update and adaptation of a previous Cochrane review, published in 2016 with searches up to September 2015 and which had included both multimorbidity and comorbidity [17]. The review is reported using the Preferred Reporting Items for Systematic Reviews and Meta-Analyses (PRISMA) guidelines for systematic reviews [19].

\section{Search strategy}

We searched MEDLINE, EMBASE, CINAHL, The Cochrane Library's five databases and two trials registers up to 9 September 2019. We also searched grey literature, in particular, the comprehensive database of the International Research Community in Multimorbidity and abstracts from annual meetings of the Society of Academic Primary Care and the North American Primary Care Research Group. We also consulted experts in the field for completed or ongoing studies, over a number of years. Search strategies are available in Additional file 1: Search Strategy.

\section{Inclusion criteria}

Study designs eligible for inclusion were randomised controlled trials (RCTs), non-randomised clinical trials (nRCTs), controlled before-after studies (CBAs), and interrupted time series analyses (ITS), meeting Cochrane Effective Practice and Organisation of Care (EPOC) quality criteria [20]. We included studies of adults with multimorbidity receiving care in a primary or community care setting. We adopted the most widely used definition of multimorbidity, that is, the co-existence of multiple chronic conditions in the same individual, usually defined as two or more conditions. We used the WHO definition of chronic disease, which is 'health problems that require ongoing management over a period of years or decades' [21]. Studies in which inclusion was based on comorbidity with a specific index condition [22] or only the age of participants (e.g. older patients) were excluded. We also excluded professional educational interventions where no care was delivered to an identified group of people with multimorbidity.

We included any type of intervention based in primary care and community settings that was specifically directed towards a group of people defined as having multimorbidity. Primary healthcare was defined as providing 'integrated, easy to access, healthcare services by clinicians who are accountable for addressing a large majority of personal healthcare needs, developing a sustained and continuous relationship with patients, and practising in the context of family and community' [23]. We anticipated that all interventions would be multifaceted given the nature of multimorbidity. We considered and reported complex interventions using the TIDIER checklist [24]. We categorised interventions based on their predominant intervention focus into the following groupings: (i) care coordination plus support for selfmanagement; (ii) support for self-management, and (iii) medicines management. The comparison was usual primary healthcare as provided in that setting.

\section{Review processes}

One author undertook an initial screen of abstracts to remove those clearly ineligible. Two authors (SS, EW) then independently screened remaining abstracts and identified full texts for screening, screened full texts 
and selected studies for inclusion. No automated tools were used in the process. Two authors (SS, EW) undertook data abstraction and cross-checked data abstraction forms. Disagreements about data abstraction were resolved by consensus between the authors. If data were missing, we contacted authors and have reported this where applicable. Two authors assessed and crosschecked the risk of bias in all included studies using Cochrane criteria (SMS and EW or BC), including allocation (sequence generation and concealment); baseline characteristics; incomplete outcome data; contamination; blinding; selective outcome reporting and other potential sources of bias. We assessed the certainty of the evidence for health-related quality of life (HRQoL), mental health, clinical, psychosocial, health service utilisation, medicines and provider behaviour outcomes using the Grading of Recommendations Assessment, Development and Evaluation (GRADE) criteria including risk of bias, consistency of effect, imprecision, indirectness and other potential criteria such as publication bias [25].

\section{Outcomes}

We based our main outcomes for this review on the core outcome set for multimorbidity [26] and these were health-related quality of life (HRQoL) and mental health outcomes. Additional outcomes included clinical outcomes, other psychosocial outcomes such as self-efficacy, health behaviours, healthcare utilisation, medicines outcomes, provider behaviour, including quality of care, patient satisfaction, harms and economic outcomes. Where data from multiple timepoints was reported, we extracted the data from the designated study end-point.

\section{Analysis}

Due to the clinical heterogeneity relating to the wide variation in participants, interventions and outcomes assessed, the main synthesis of the results is narrative. This decision was made by all authors on reviewing the range of participants and interventions as presented in the Table of Included studies. We undertook metaanalysis where it was appropriate to combine studies in terms of participants, interventions or outcomes and in these cases we used risk ratios or mean differences in the synthesis. We did not impute any missing data, and clustering in original studies was already incorporated in included study estimates within the meta-analyses. Metaanalysis was undertaken in the Revman software for the main outcome HRQoL using a random-effects model with generic inverse variance, which incorporates cluster effects within estimates for each included study. We also conducted a random effects meta-analysis of mean difference in two studies for the additional outcome of selfefficacy using.

\section{Results}

\section{Results of the search}

From a total of 38,489 original citations (after duplicates were removed) (Fig. 1), 205 full texts were reviewed. Of these, 189 articles were excluded and a total of 16 RCTs were included. Sixteen studies contributed data for inclusion in the narrative synthesis and 7 provided data for meta-analyses.

\section{Included studies and participants}

A total of 16 RCTs with 4753 participants were included. Eight had a parallel design [27-34], and eight had a cluster design [35-42], with one of these having a cluster stepped wedge design [37]. Intervention duration varied from 6 weeks to 18 months, with the majority lasting 6 to 12 months. Most studies collected follow-up data at intervention completion. The studies were conducted in Germany $(n=4)$, UK $(n=3)$, USA $(n=3)$, Canada $(n=$ $2)$, Ireland $(n=2)$ and one study each in Spain and Australia. All studies were funded publicly by government agencies or through charitable or university foundations. The definition of multimorbidity varied across studies though all used some additional measure of complexity beyond the standard multimorbidity definition of 2 or more conditions. These included higher numbers of conditions or additional factors such as high health service use or polypharmacy. The mean number of conditions in patients in the 14 studies that reported this, ranged from 3 to 12.7 conditions (see Table 1), suggesting that included studies were targeting those with more complex multimorbidity. Whilst six of the 16 studies targeted older patients, the mean age of included patients ranged from 50 to 80.5 years with 10 of the 16 included studies having participants with a mean age $>70$ years indicating that most studies included older patients (see Table 1).

\section{Description of interventions and comparators}

The interventions were all multifaceted (Table 1). Few studies specifically reported patient involvement in intervention design though this was becoming more common in later studies $[38,40]$. Studies were grouped into three broad groupings of care-coordination plus selfmanagement support (CC/SMS), self-management support (SMS) and medicines management. Eight of the 16 included studies examined CC/SMS type interventions and involved multifaceted interventions that targeted the coordination of care, healthcare providers and also provided self-management support for patients [27, 30, $31,35,38,40-42]$. Four studies reported on SMS interventions that did not have a clear link to the patients' healthcare provision $[28,29,33,34]$. Three of these were group-based programmes based on the Chronic Disease Self-Management Support programme and the fourth 


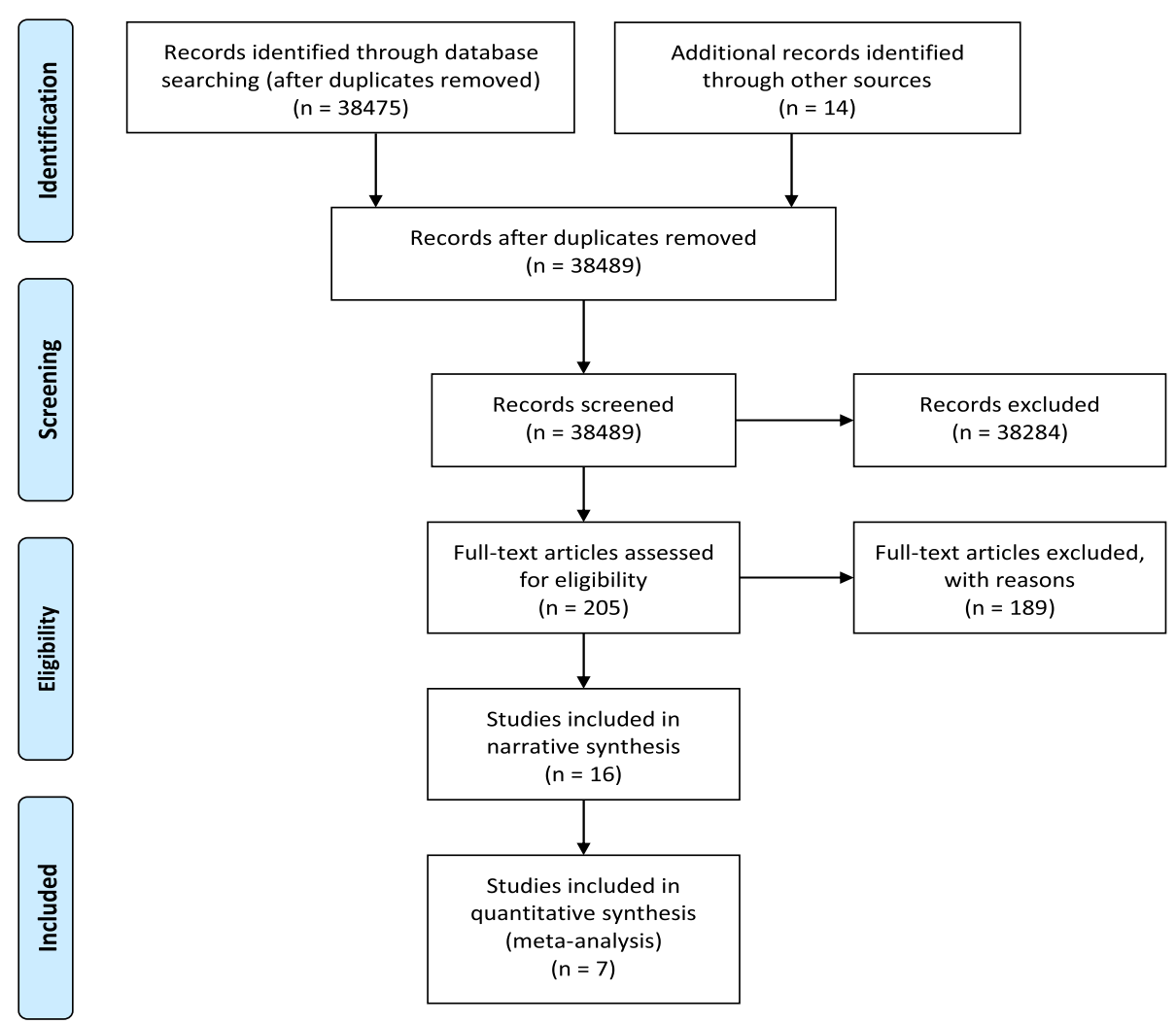

Fig. 1 Flow diagram of studies screened

involved health promoters working from community clinics to provide individual self-management support [28]. Four studies focused primarily on medicines management but specifically targeted patients with multimorbidity $[32,36,37,39]$. In the majority of included studies, the comparator was usual primary healthcare.

\section{Risk of bias and certainty of the evidence}

The studies were all RCTs and overall there was low or unclear risk of bias with only one study having a high risk of bias in two of the eight risk of bias domains, blinding and protection against contamination [32] (see Fig. 2). The most common issue leading to a judgement of unclear risk of bias was lack of clarity around blinding, which can be a challenge in these types of interventions. The risk of bias for individual studies is presented in Additional file 2: Figure 1.

\section{Certainty of the evidence}

In general, whilst all the included studies were RCTs, the main concerns related to inconsistency and imprecision. For all intervention types, we downgraded the evidence for all outcomes to low certainty due to serious concerns about inconsistency and imprecision (see Additional file 3: Grade Working Sheets). This reflects the clinical heterogeneity of participants, interventions and outcomes assessed and the likelihood that future studies may change our review findings.

\section{Effects of interventions}

The effects of intervention on the main and additional outcomes are presented in Table 2.

Overall, the results suggest that all intervention types targeting patients with multimorbidity probably make little or no difference to the main outcomes of HRQoL ( $n$ $=10)[29,30,32,33,37-42]$ or mental health outcomes $(n=6)[11,29,33,40-42]$. Five of the 10 studies with HRQoL outcomes reported EQ-5D scores that could be included in a meta-analysis [11,33, 39-41], with a mean difference of 0.03 (95\% CI -0.01 to $0.07, I^{2}=39 \%$ ) (see Fig. 3), consistent with the overall effect suggesting no difference in this outcome. The five studies included in the HRQoL meta-analysis had low risk of bias overall.

For additional outcomes, there was little or no effect on clinical outcomes $(n=2)$ or on the majority of other psychosocial outcomes $(n=11)$, including self-efficacy $(n=$ 4). A meta-analysis of studies with available data for selfefficacy $(n=2)$ found a mean difference in self-efficacy 


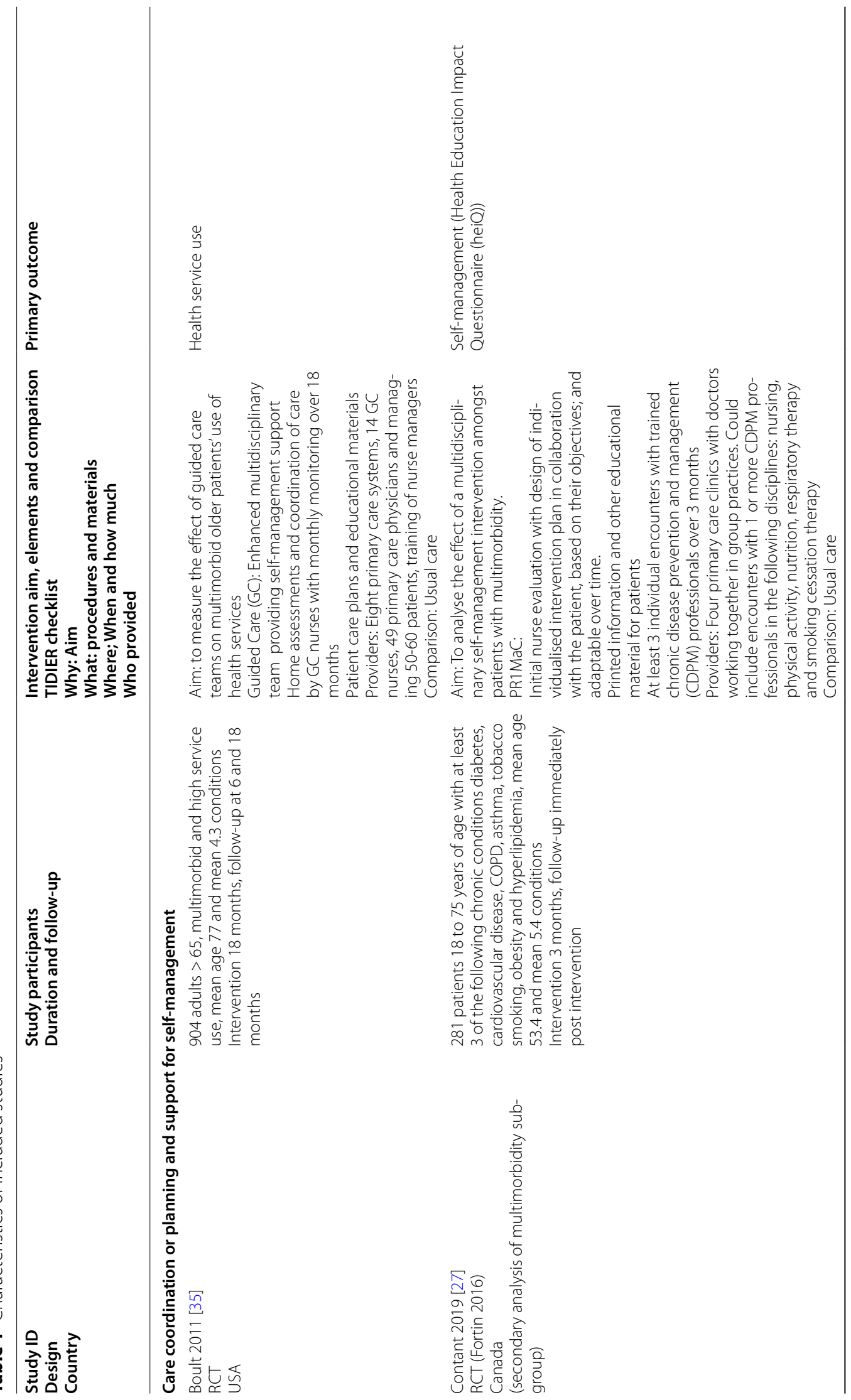




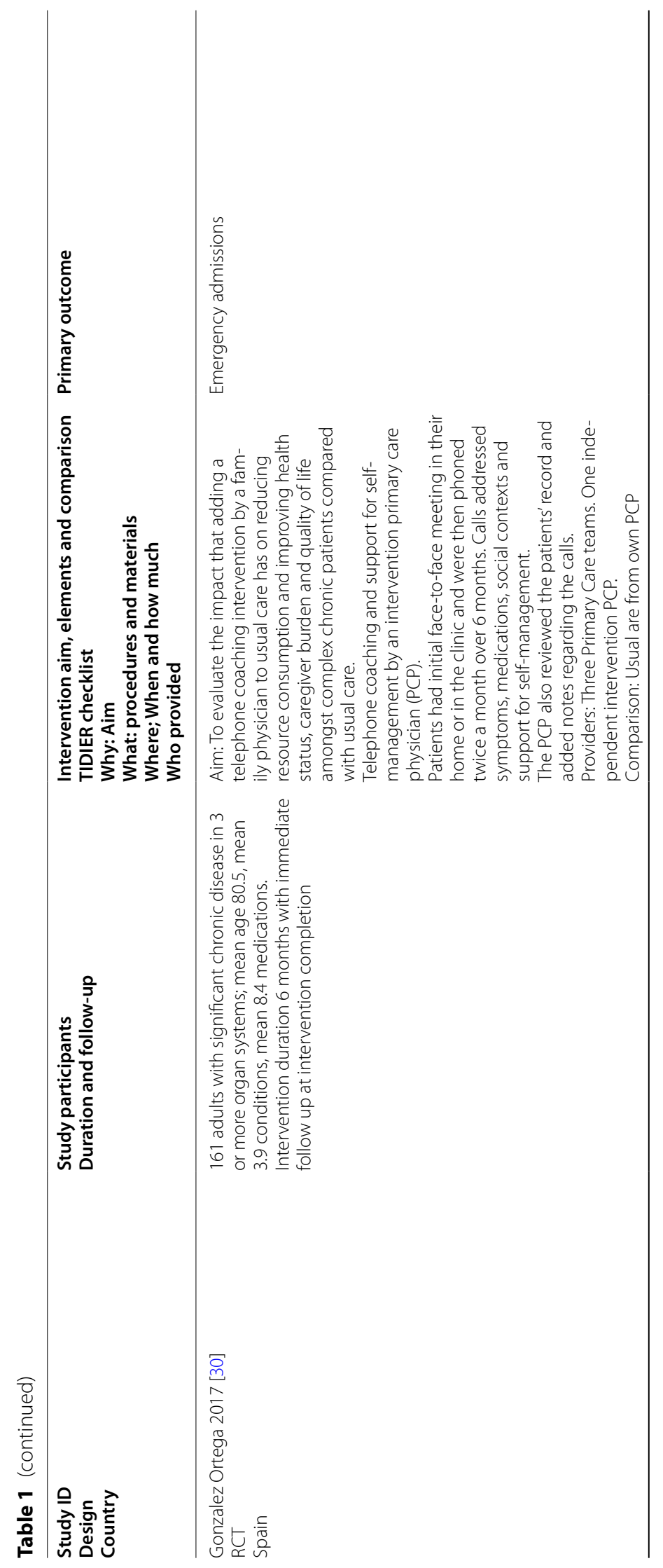




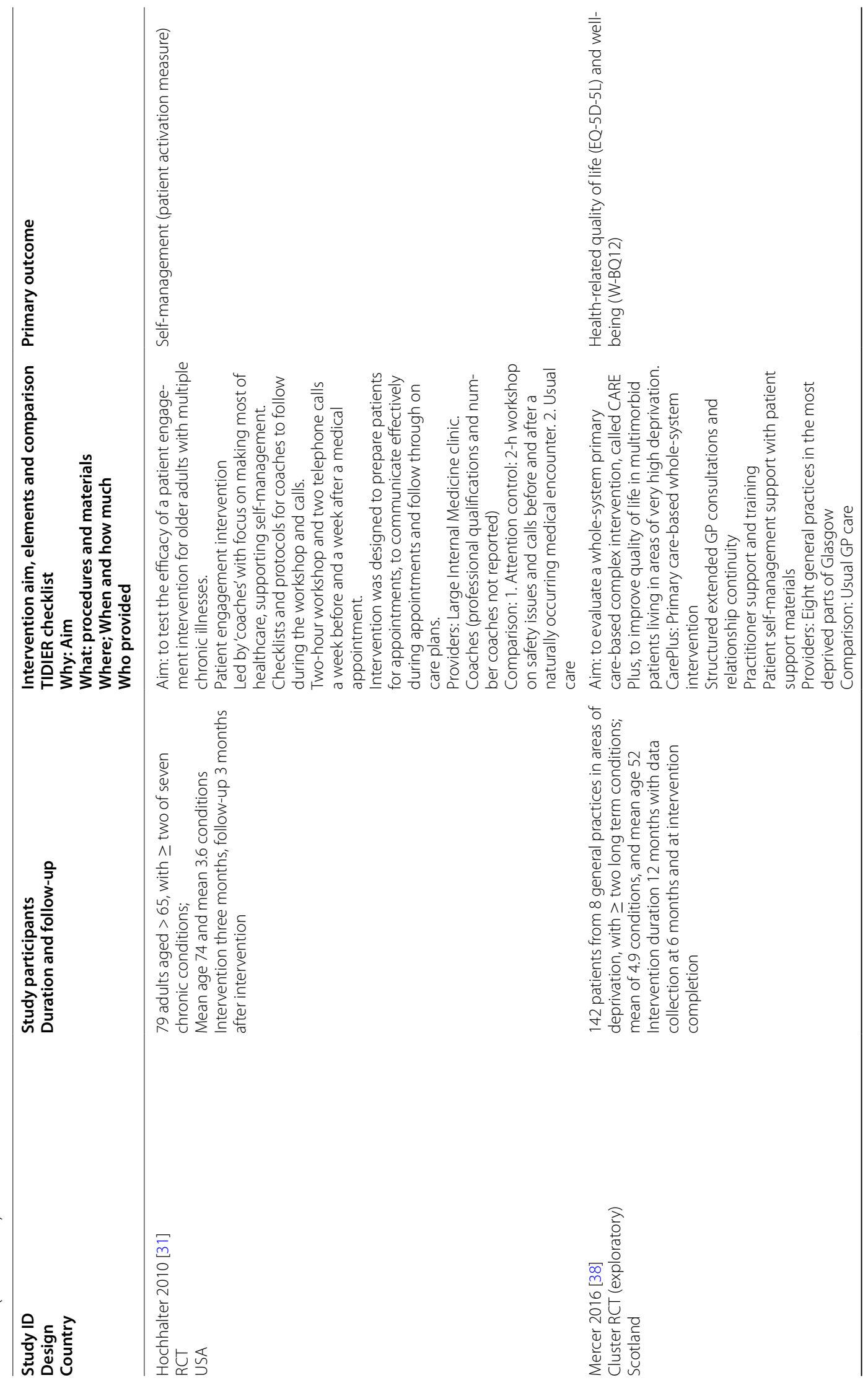




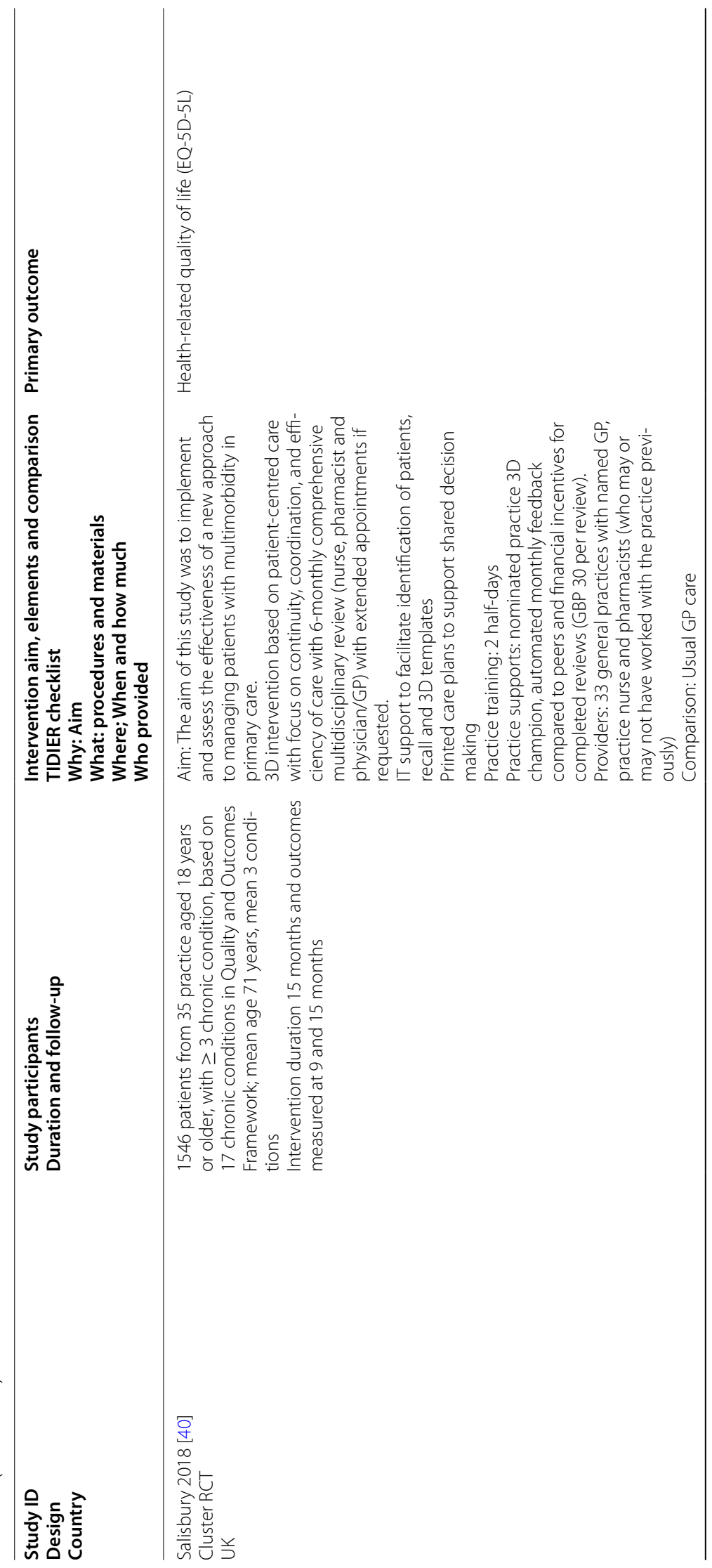




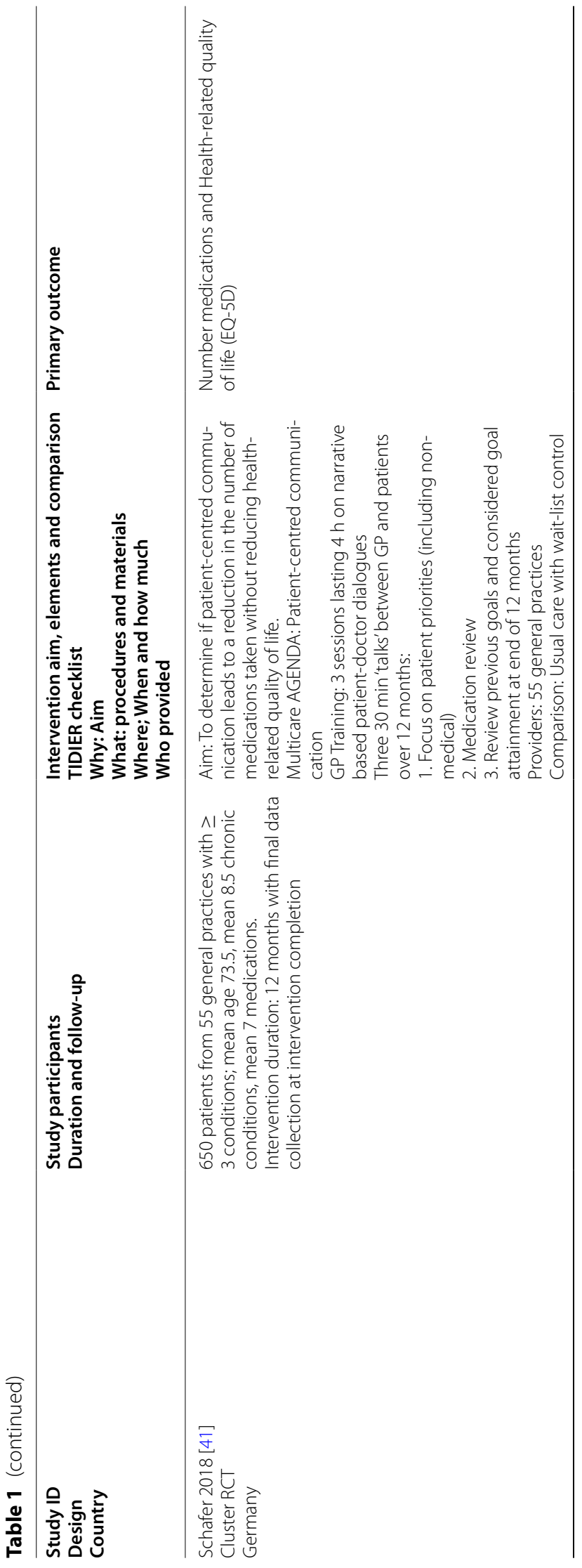




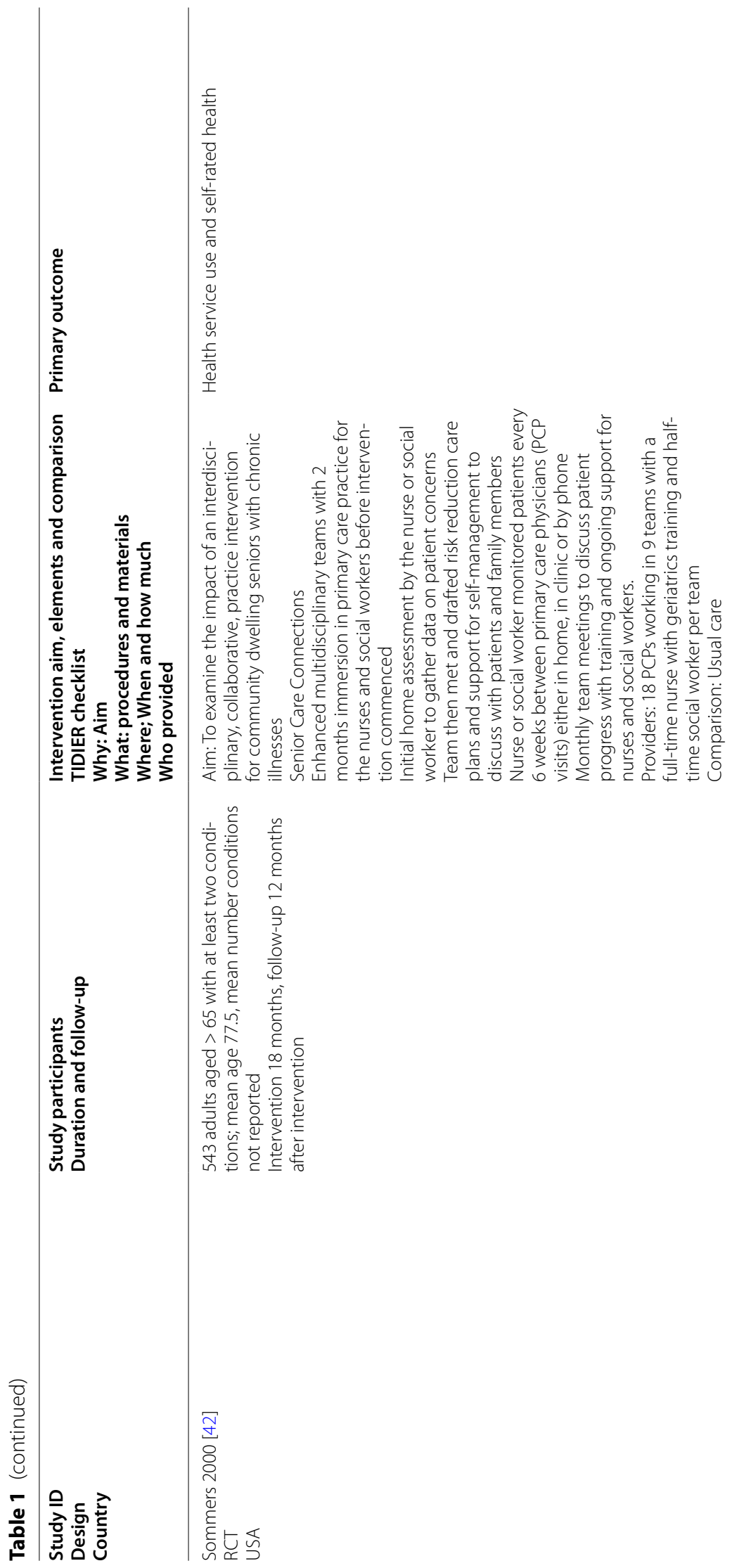




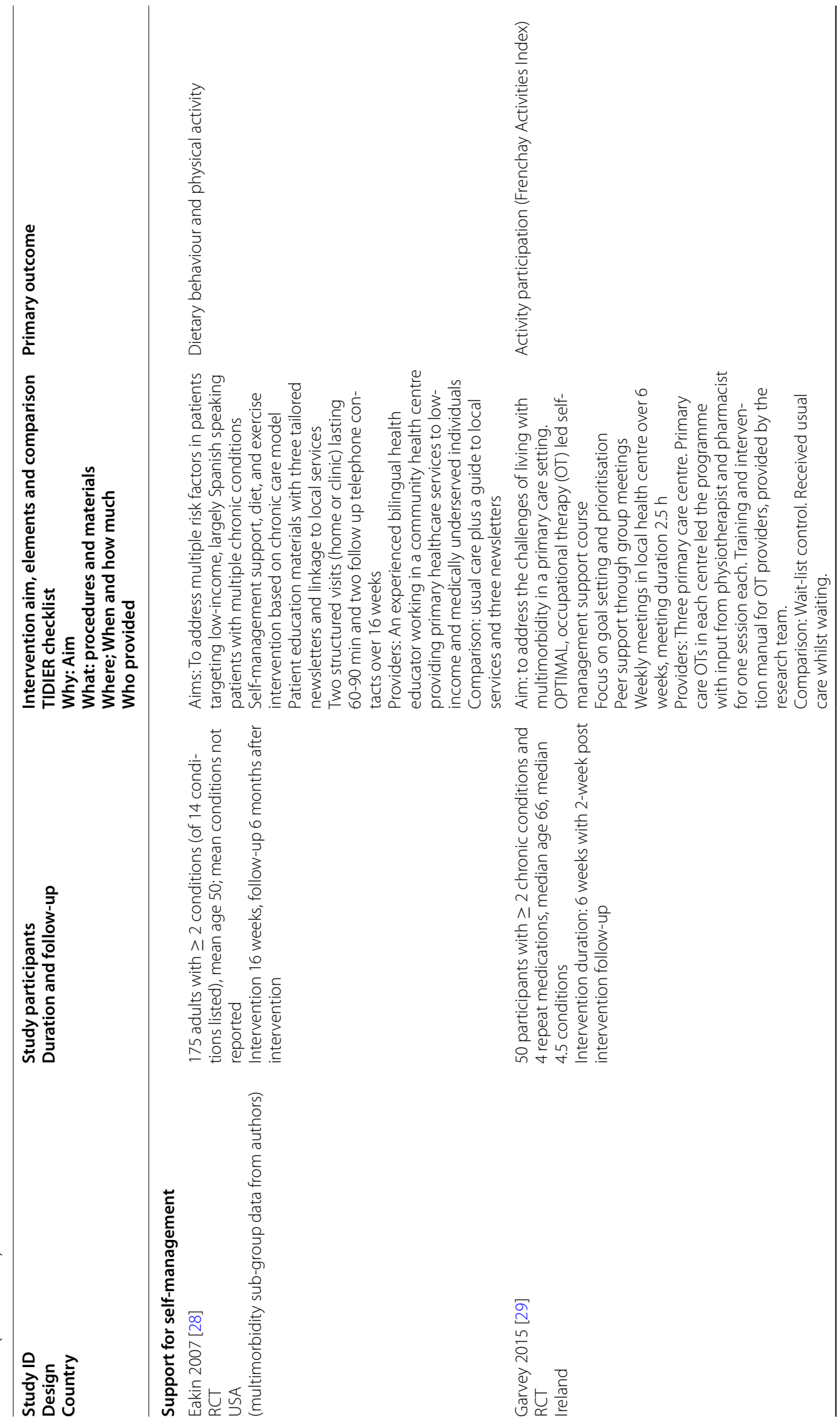




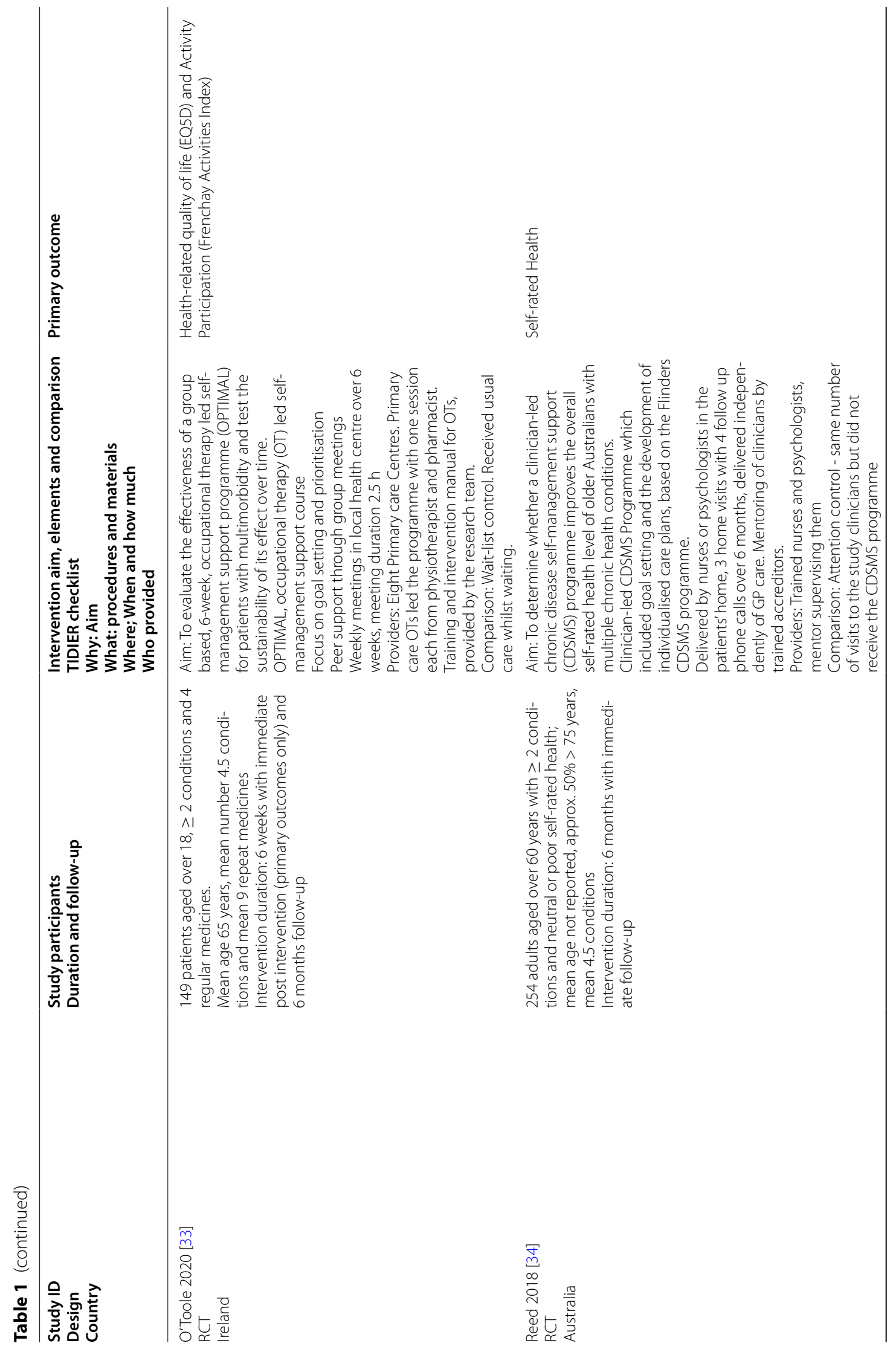




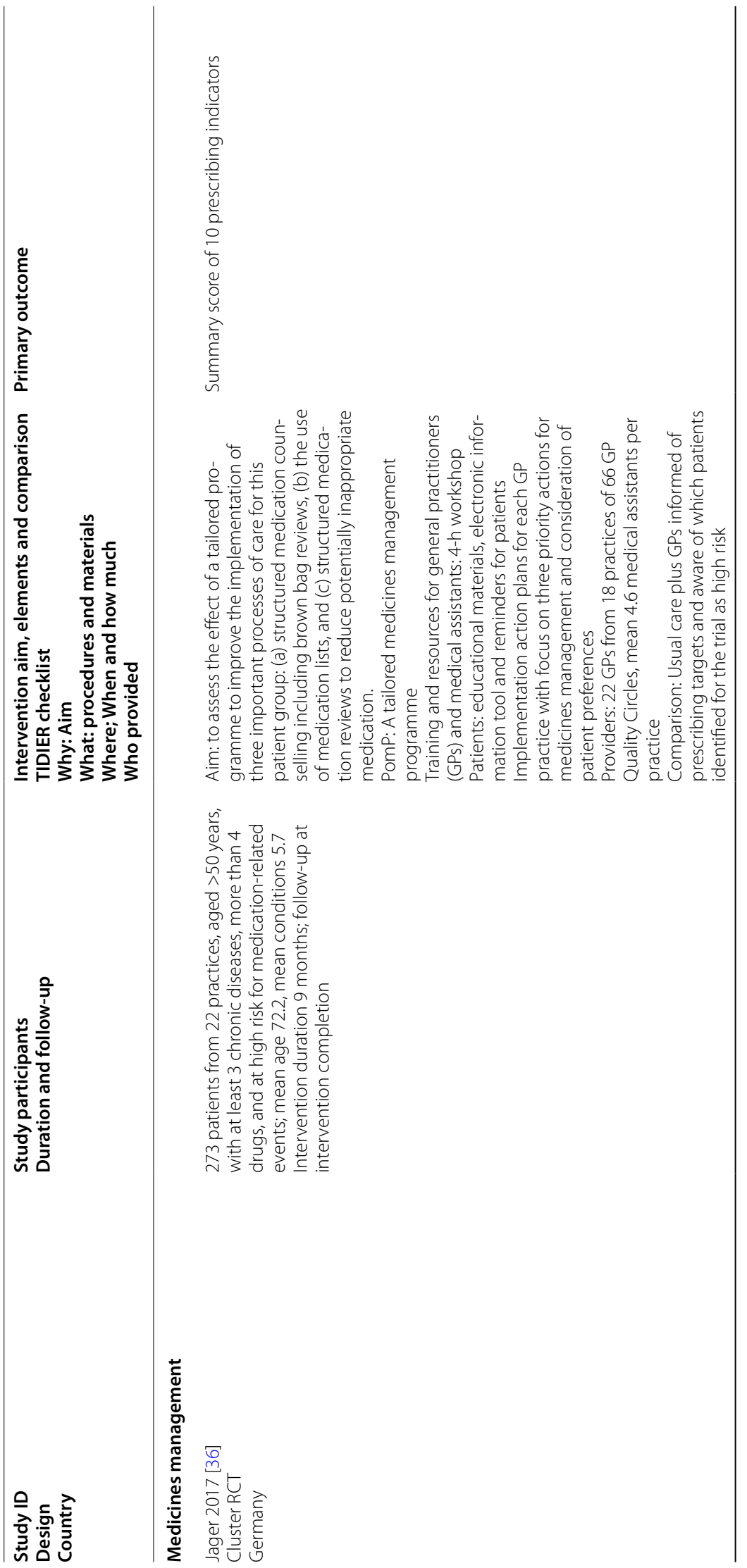




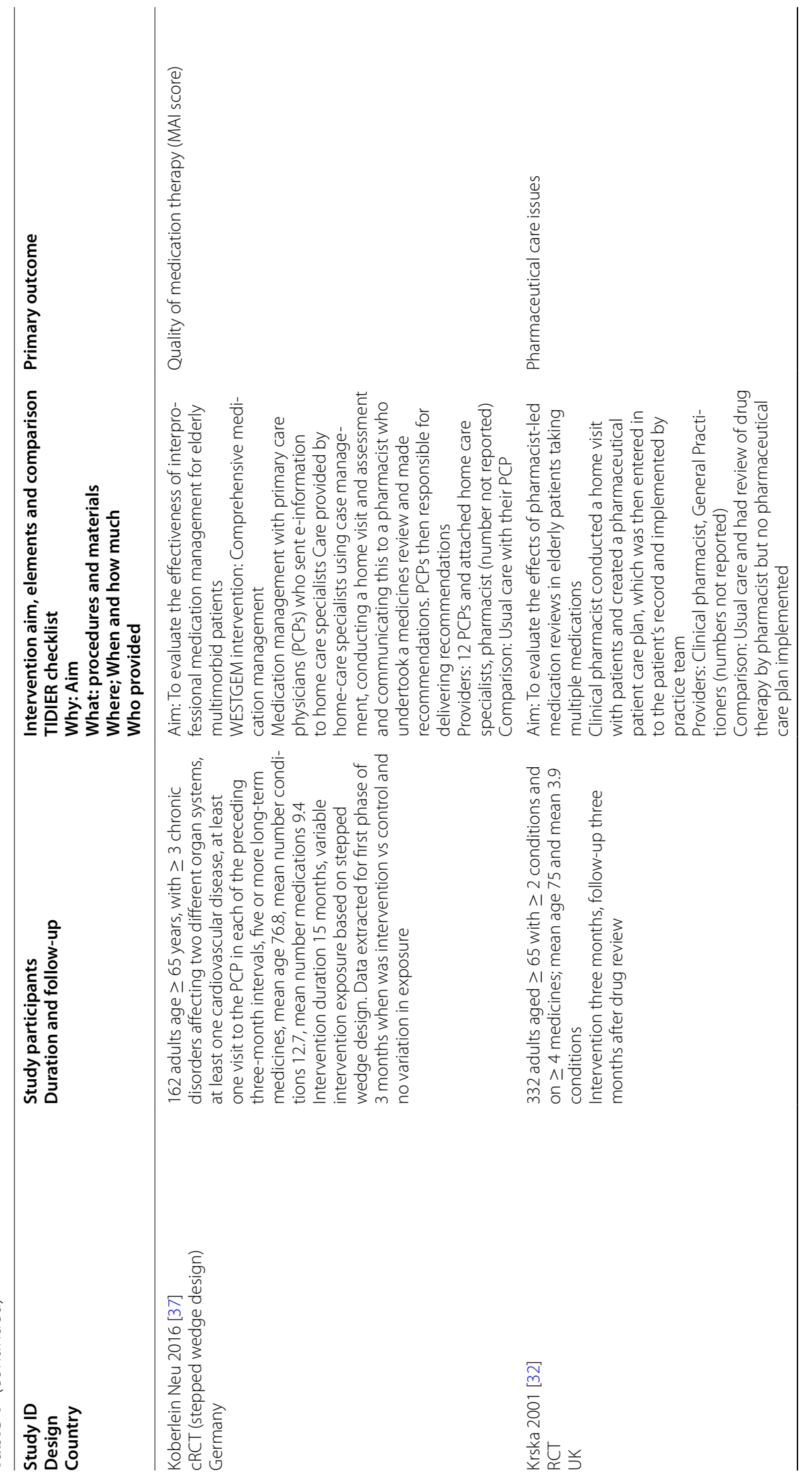




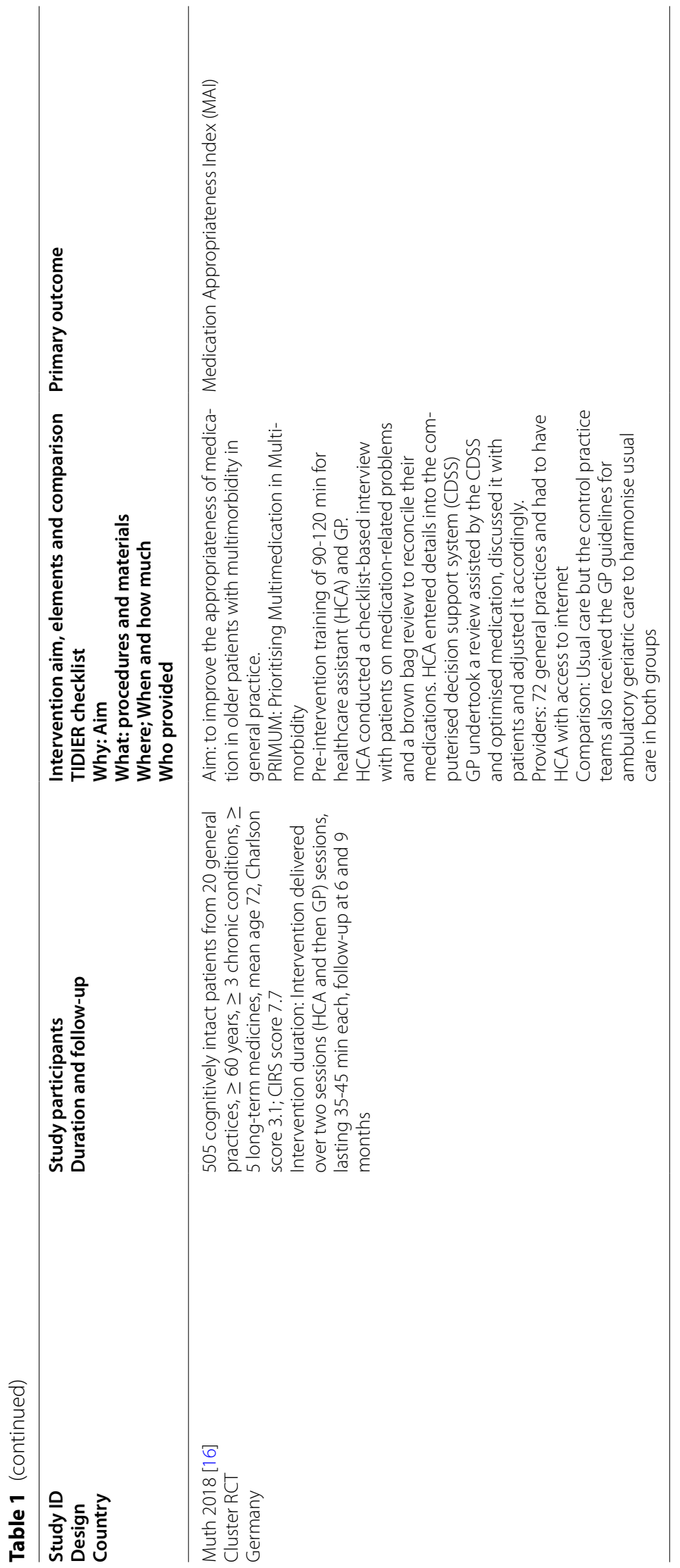




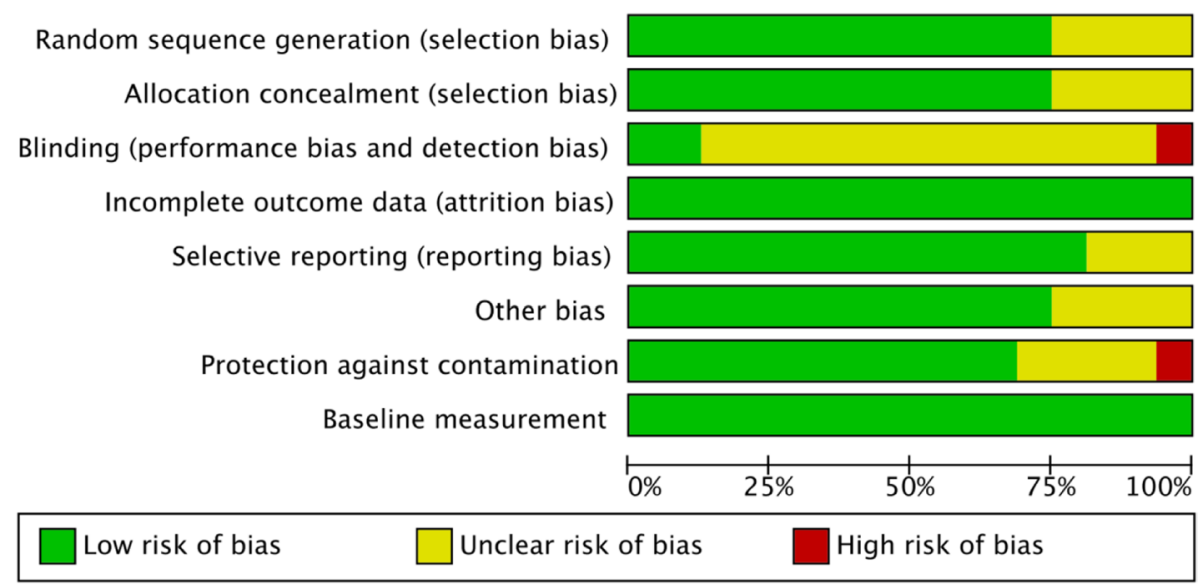

Fig. 2 Risk of bias across included studies

scores of $0.92,95 \%$ CI -0.04 to $1.88, I^{2}=63 \%$ (see Additional file 4: Figure 2). There were mixed effects on function and activity $(n=4)$ and patient health behaviours $(n$ $=2$ ). There was little or no effect on healthcare utilisation $(n=9)$, though numbers of hospital admissions in most studies were small. There was also little or no effect on medicine outcomes $(n=9)$. Five of the care coordination/self-management support studies reported little or no effect on numbers of medicines or medication adherence. There were mixed effects on medicine outcomes in the four studies with a medicines management type intervention, which reported mixed results in medication appropriateness and potentially inappropriate prescribing. There was some improvement in healthcare provider behaviours in two of the three care coordination/selfmanagement support studies reporting these outcomes but mixed effects on patient satisfaction with services $(n=3)$. Only one of the 16 included studies reported a potential adverse event relating to prescribing of analgesics but no other studies reported harms. Only two of the 16 studies reported full cost-effectiveness analyses to date with one reporting cost-effectiveness [38] and the other reporting equivocal results [40].

\section{Discussion}

We identified 16 RCTs eligible for inclusion with a low risk of bias overall. The majority of studies included older patients with at least three conditions. Interventions were complex and multifaceted and could be broadly categorised into three groups involving care coordination and/or self-management support and medicines management. However, the heterogeneous populations and interventions make comparison of intervention effects difficult. Overall, despite 16 RCTs examining interventions for multimorbidity, there is still no clear high quality evidence to guide healthcare delivery with little effect on the main outcomes of health related quality of life or mental health outcomes. There was no clear pattern of effect by type of intervention. Care coordination/self-management support type interventions may improve the patient experience of care though this is based on a small number of studies and is of low certainty. Self-management support interventions may be associated with minimal improvements in patient health behaviours. Medicines management interventions had mixed effects but in some studies there may have been minimal room for improvement. However, these conclusions are based on small numbers of studies and are of low certainty.

The results suggest that future research for multimorbidity should consider areas such as the patient experience of care, optimising medicines management and targeted patient health behaviours such as exercise though this is based on a small numbers of studies and low certainty evidence. Twelve of the 16 included studies aimed to improve self-management support in patients. Many self-management support interventions are based on the original Chronic Disease Selfmanagement Support Programme, and our results are consistent with the Cochrane Review on lay-led selfmanagement support programmes, which concluded that whilst these interventions may have modest shortterm effects on confidence to manage conditions, there is no clear evidence that these interventions improve psychological health, symptoms or health-related quality of life, or that they significantly alter healthcare use [43]. Addressing functional difficulties has been identified as a patient priority [15], but we found mixed effects on function and disability. Economic outcomes 


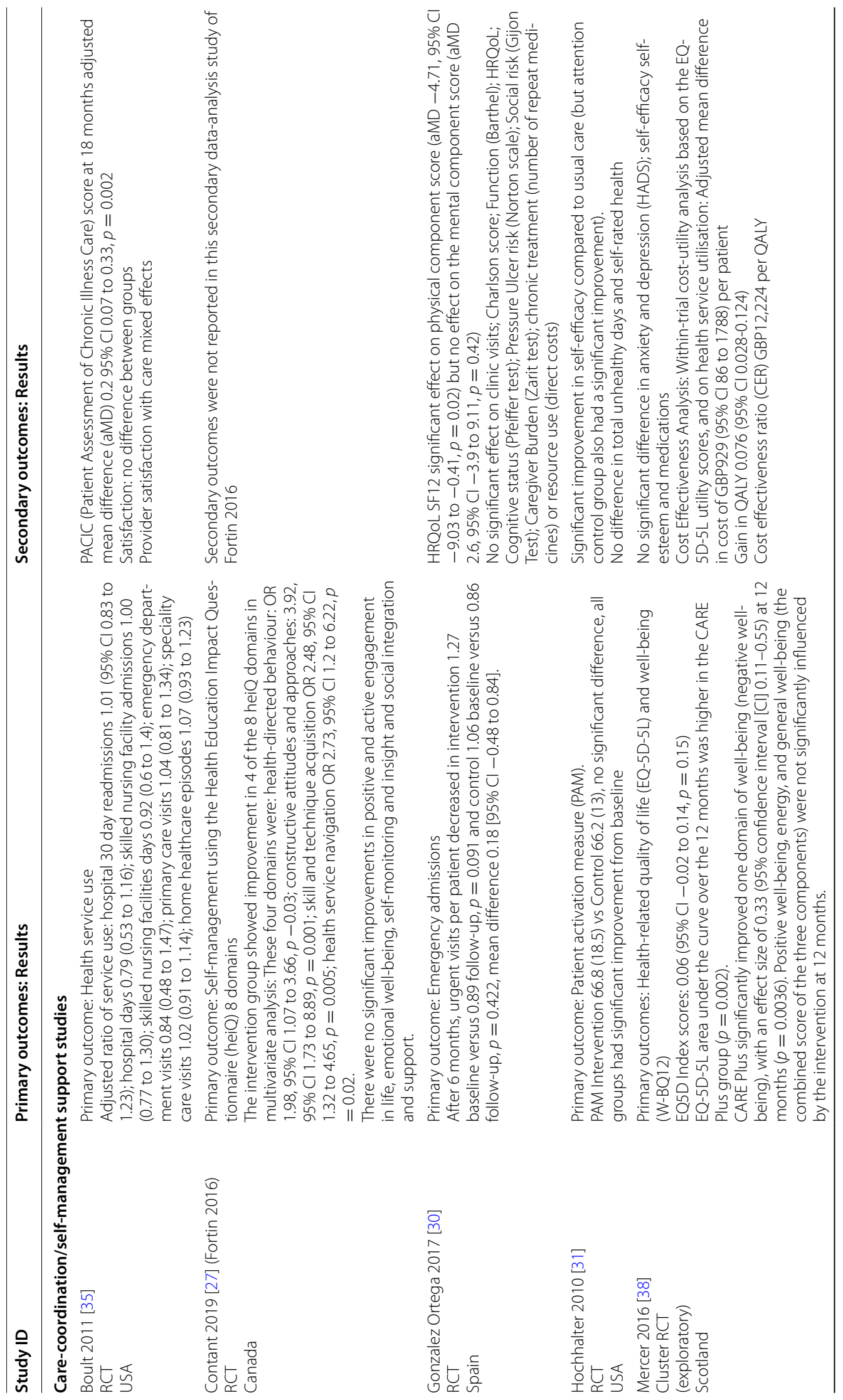




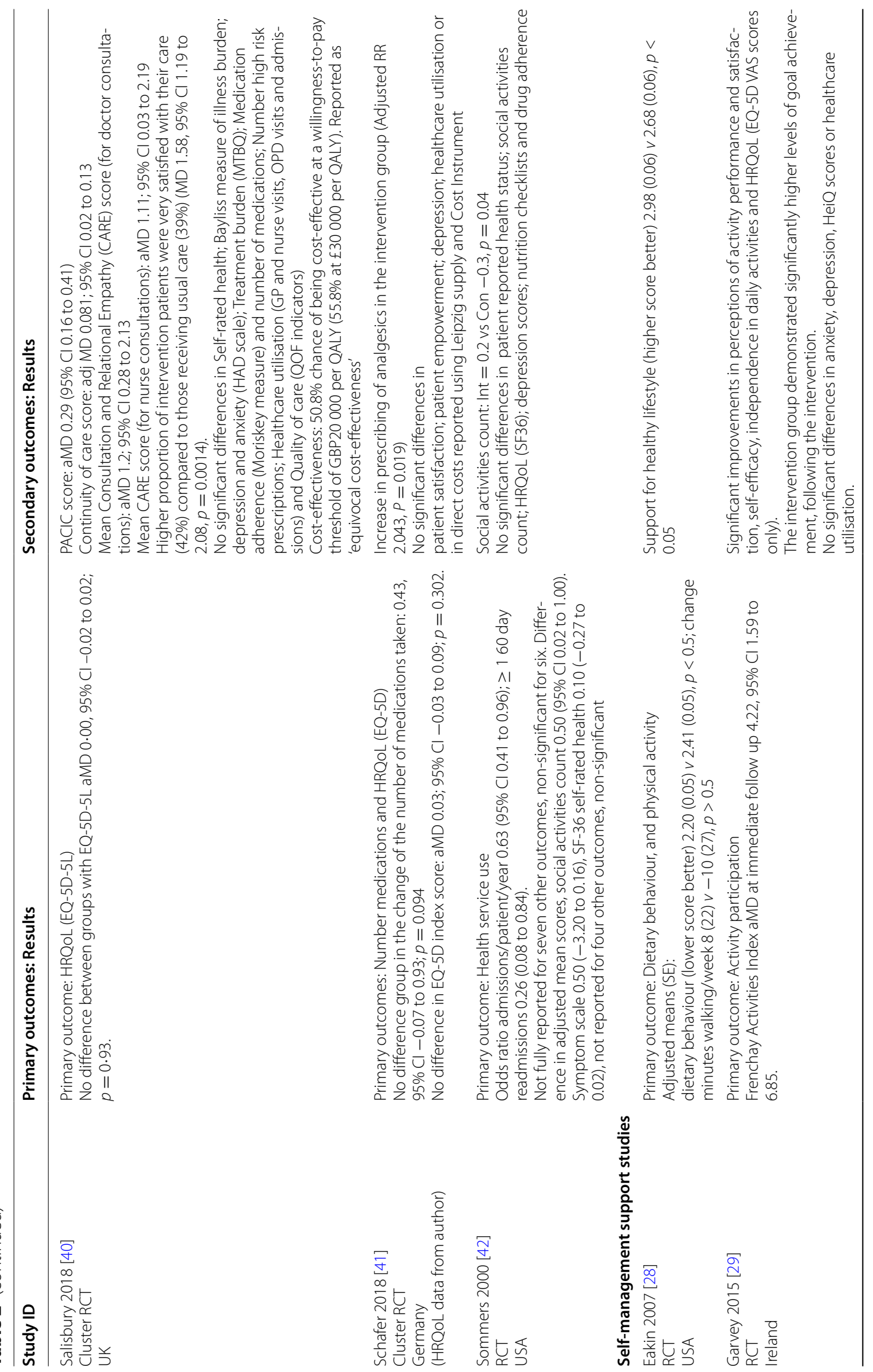




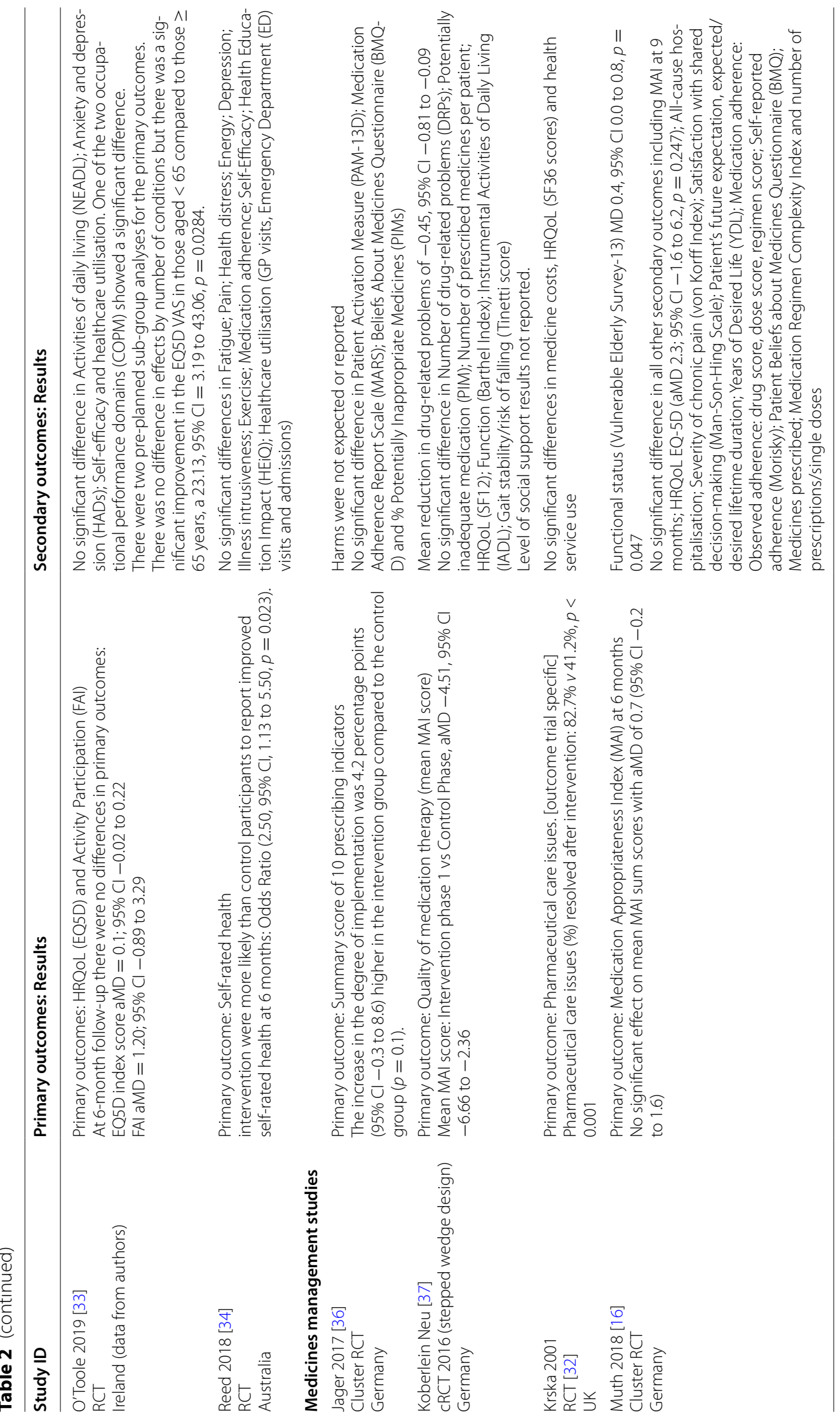




\begin{tabular}{|c|c|c|c|c|c|}
\hline Study or Subgroup & Mean Difference & SE & Weight & $\begin{array}{l}\text { Mean Difference } \\
\text { IV, Random, } 95 \% \mathrm{CI}\end{array}$ & $\begin{array}{c}\text { Mean Difference } \\
\text { IV, Random, 95\% CI }\end{array}$ \\
\hline \multicolumn{6}{|c|}{ 1.1.1 Care coordination interventions } \\
\hline Mercer 2016 & 0.06 & 0.04 & $17.2 \%$ & $0.06[-0.02,0.14]$ & 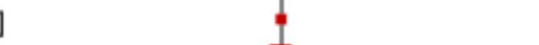 \\
\hline Salisbury 2018 & 0 & 0.01 & $48.9 \%$ & $0.00[-0.02,0.02]$ & \\
\hline $\begin{array}{l}\text { Schafer } 2018 \\
\text { Subtotal }(95 \% \mathrm{CI})\end{array}$ & 0.03 & 0.03 & $\begin{array}{l}24.7 \% \\
90.8 \%\end{array}$ & $\begin{array}{l}0.03[-0.03,0.09] \\
0.01[-0.02,0.04]\end{array}$ & ] \\
\hline \multicolumn{6}{|c|}{$\begin{array}{l}\text { Heterogeneity: } \mathrm{Tau}^{2}=0.00 ; \mathrm{Chi}^{2}=2.82, \mathrm{df}=2(\mathrm{P}=0.24) ; \mathrm{I}^{2}=29 \% \\
\text { Test for overall effect: } \mathrm{Z}=0.90(\mathrm{P}=0.37)\end{array}$} \\
\hline \multicolumn{6}{|c|}{ 1.1.3 Self-management support studies } \\
\hline $\begin{array}{l}\text { O'Toole } 2019 \\
\text { Subtotal }(95 \% \mathrm{CI})\end{array}$ & 0.1 & 0.06 & $\begin{array}{l}9.2 \% \\
9.2 \%\end{array}$ & $\begin{array}{l}0.10[-0.02,0.22] \\
0.10[-0.02,0.22]\end{array}$ & \\
\hline \multicolumn{6}{|c|}{$\begin{array}{l}\text { Heterogeneity: Not applicable } \\
\text { Test for overall effect: } Z=1.67(P=0.10)\end{array}$} \\
\hline \multicolumn{6}{|c|}{ 1.1.5 Medicines management interventions } \\
\hline $\begin{array}{l}\text { Muth } 2018 \\
\text { Subtotal }(95 \% \mathrm{CI})\end{array}$ & 2.3 & 2 & $\begin{array}{l}0.0 \% \\
0.0 \%\end{array}$ & $\begin{array}{r}2.30[-1.62,6.22] \\
2.30[-1.62,6.22]\end{array}$ & \\
\hline \multicolumn{6}{|c|}{$\begin{array}{l}\text { Heterogeneity: Not applicable } \\
\text { Test for overall effect: } Z=1.15(P=0.25)\end{array}$} \\
\hline Total $(95 \% \mathrm{CI})$ & & & $100.0 \%$ & $0.03[-0.01,0.07]$ & \\
\hline \multicolumn{6}{|c|}{$\begin{array}{l}\text { Heterogeneity: } \mathrm{Tau}^{2}=0.00 ; \mathrm{Chi}^{2}=6.53, \mathrm{df}=4(\mathrm{P}=0.16) ; \mathrm{I}^{2}=39 \% \\
\text { Test for overall effect: } \mathrm{Z}=1.36(\mathrm{P}=0.17) \\
\text { Test for subqroup differences: } \mathrm{Chi}^{2}=3.22 . \mathrm{df}=2(\mathrm{P}=0.20), \mathrm{I}^{2}=37.9 \%\end{array}$} \\
\hline
\end{tabular}

tended to focus on simple cost analyses comparing direct costs for intervention and control participants.

This review includes one of the largest studies undertaken in multimorbidity, the 3D study, which showed no difference in its primary outcome (HRQoL), despite having an intervention carefully designed to address the known challenges and treatment burden of multimorbidity and focusing on dimensions of health, depression and drugs (3D) [40]. However, the 3D intervention did improve patient-centred care, which may well be a reasonable end-point in itself [44]. One of the other larger multimorbidity studies, the Guided Care study, targeted high-risk older patients with multimorbidity, but found no overall effect on hospital admissions [35]. However, a pre-planned sub-group analysis indicated improvements in one of the participating healthcare organisations (Kaiser-Permanente, an insurance based care system in the USA, $n=365,43 \%$ of full sample). Boult et al. postulated that this result may have been related to the fact that care was already more organised and structured in this system, so that the Guided Care intervention may simply have extended the existing approaches used in that setting, whereas its implementation was more challenging in less organised systems [35].
Even when interventions are targeted at a specific problem such as polypharmacy or potentially inappropriate prescribing, they may not be effective unless they target the right patients. For example, we found that, of the four studies with medicines management interventions, two included participants with minimal baseline prescribing problems making it difficult to improve outcomes. The Cochrane Review of interventions for enhancing medication adherence concluded that 'current methods of improving adherence for chronic health problems are mostly complex and not very effective' and suggests further research is needed [45]. Managing medicines is a key part of managing multimorbidity and features as a key element of existing clinical guidelines for multimorbidity with an emphasis on targeting those with more complex polypharmacy, i.e. on 15 or more regular medicines [13, $15,16]$.

The majority of the studies in this review included older people, even when younger adults were eligible for inclusion. It is important to address the needs of younger individuals as there are additional issues to consider relating to employability and absenteeism. Individuals in the poorest socioeconomic groups are more likely to develop multimorbidity at a younger age [10]. This review includes a trial that specifically targeted socioeconomically 
disadvantaged people with multimorbidity [38]. This CarePlus study had a multi-level intervention supporting practitioners and patients and reported a cost per qualityadjusted life year of GBP 12,000 which is well within the recommended funding threshold for effective healthcare interventions in the UK.

The most consistent intervention element across all included studies was the use of case managers, but even these varied in that some were clinical case managers and others were administrative managers. Systematic reviews of community-based case management in general have indicated uncertain effects with improvements in client and professional satisfaction with care and reductions in caregiver strain, but no impact on healthcare utilisation [46]. An international group of multimorbidity researchers recently published a systematic review of clinical guidelines for multimorbidity and polypharmacy which also found variation in the eight clinical guidelines reviewed and a need for greater consensus on multimorbidity definitions and management approaches [16].

The largely negative findings in this review likely relates to the challenges of multimorbidity in terms of heterogeneity of populations and potential interventions. Whilst it could be argued that multimorbidity care may not offer any advantages over care for single chronic conditions, qualitative research with patients and practitioners highlights the challenges they face managing multiple conditions in medical systems that have largely been designed around single chronic condition care $[47,48]$. The NICE Guidance on Multimorbidity calls for a re-orientation of care to address multimorbidity and highlights the importance of recognising and addressing treatment burden for patients $[13,14]$.

\section{Strengths and limitations of the review}

Multimorbidity is a complex area because the characteristics of participants can vary depending on definitions used. This limits the potential to combine study results reasonably for meta-analysis. This clinical heterogeneity has led some to question whether defined interventions can be developed for this population. Despite this challenge, there are increasing numbers of interventions being developed and evaluated. The review was carried out using the updated Cochrane Handbook for Systematic Reviews of Interventions [49]. Potential limitations in the search process for this review related to the lack of a MeSH term for multimorbidity, though this has now been addressed. This meant that we originally had to use broad search terms which led to a high yield of citations to be searched. Given the very high number of titles screened this was done by only one author and this is a limitation of the review. However, the authors are active researchers in the field of multimorbidity and are unaware of any potentially eligible studies that were missed by the search. We were also unable to retrieve some missing data from authors. However, as limited meta-analyses were undertaken this did not lead to any appreciable measurement bias. The usual limitations relating to publication bias apply, but we have searched the grey literature and contacted experts in the field to try to identify published and ongoing trials in this area. A further limitation of the review is that the last full comprehensive search update was conducted in September 2019. In view of this limitation, we reviewed the comprehensive database of the International Research Community in Multimorbidity to review potential studies published between 2019 and 2021 [50]. Only two potentially eligible trials [51, 52] were identified and the results of these studies would not change the conclusions of the current systematic review.

The variation in definitions in the included studies included highlights the need for clear reporting of participant characteristics. Without these definitions, the generalisability or applicability of studies for people with multimorbidity will be uncertain [53]. When designing interventions, researchers need to be clear about the theoretical assumptions underlying the intervention, consider its individual components and the evidence base behind each, and then link these to outcomes. There is a specific framework to support the development of interventions for multimorbidity, which highlights the potential for other study designs, such as stepped-wedge designs that may be more suited to multimorbidity intervention initiatives and that can be undertaken within service/research partnerships [54]. There is also room to improve patient and public participation (PPI) in multimorbidity trials with only a few of the more recent studies in this review incorporating PPI $[38,40]$. People with multimorbidity are more likely to experience what is referred to as 'treatment burden', that is, the effort needed to engage in the multiple treatments offered to them can actually make their lives more difficult [14]. Only one study included a treatment burden measure and reported little or no difference in this outcome [40]. Outcomes for this review were based on the core outcome set for multimorbidity, which can also inform outcome selection for future studies so that we can more easily compare interventions across different studies [26].

\section{Conclusion}

This review highlights the growing evidence underpinning interventions to improve outcomes for people with multimorbidity. Despite the number of randomised controlled trials, there are remaining uncertainties 
about the effectiveness of interventions for people with multimorbidity. Our findings suggest that future research for multimorbidity should consider areas such as the patient experience of care, optimising medicines management and targeting patient health behaviours such as exercise. There are significant numbers of ongoing multimorbidity studies, all of which will generate much needed further evidence to support the development of healthcare services to improve outcomes for patients with multimorbidity.

\section{Supplementary Information}

The online version contains supplementary material available at https://doi. org/10.1186/s13643-021-01817-z.

Additional file 1. Search Strategies.

Additional file 2: Figure 1. Risk of bias in included studies.

Additional file 3. Grade Working sheets.

Additional file 4: Figure 2. Meta-analysis of self-efficacy scores.

\section{Acknowledgements}

None.

\section{Authors' contributions}

Susan Smith (SS) conceived and designed the review. Emma Wallace (EW), Barbara Clyne (BC) and Susan Smith (SS) assessed studies for inclusion, and extracted data from included studies. Fiona Boland (FB) provided statistical support for the meta-analyses. All authors were involved in writing the review drafts. The authors read and approved the final manuscript.

\section{Funding}

Susan M Smith is the PI on the Health Research Board funded Collaborative Doctoral Award in Multimorbidity (HRB CRC-2014-1), which has supported her engagement in this work. This work was also supported by the Health Research Board Primary Care Research Centre (HRB CDA-2018-003). BC is supported by a HRB Emerging Investigator Award (HRB EIA-2019-09).

\section{Availability of data and materials}

Data available for the authors.

\section{Declarations}

\section{Ethics approval and consent to participate}

This is a secondary data analysis of published and anonymised data, so it is not applicable.

\section{Consent for publication}

Not applicable.

\section{Competing interests}

None declared.

\section{Author details}

${ }^{1}$ Department of General Practice and HRB Centre for Primary Care Research, Royal College of Surgeons, 123 St Stephens Green, Dublin 2, Ireland. 'Data Science Centre and HRB Centre for Primary Care Research, Royal College of Surgeons, 123 St Stephens Green, Dublin 2, Ireland. ${ }^{3}$ Department of Family Medicine and Emergency Medicine, Université de Sherbrooke, Quebec, Canada.

Received: 7 January 2021 Accepted: 16 September 2021

Published online: 20 October 2021

\section{References}

1. Boyd CM, Fortin M. Future of multimorbidity research: how should understanding of multimorbidity inform health system design? Future Multimorbidity Res How Should Underst Multimorbidity Inform Health Syst Des. 2010;32:451-74.

2. Fortin M, Soubhi H, Hudon C, Bayliss E, van den Akker M. Multimorbidity's many challenges. BMJ. 2007;334(7602):1016-7.

3. Tinetti ME, Green AR, Ouellet J, Rich MW, Boyd C. Caring for patients with multiple chronic conditions. Ann Intern Med. 2019. https://doi.org/10. 7326/M18-3269.

4. Menotti A, Mulder I, Nissinen A, Giampaoli S, Feskens EJ, Kromhout D. Prevalence of morbidity and multimorbidity in elderly male populations and their impact on 10-year all-cause mortality: the FINE study (Finland, Italy, Netherlands, Elderly). J Clin Epidemiol. 2001;54(7):680-6.

5. Payne RA, Abel GA, Guthrie B, Mercer SW. The effect of physical multimorbidity, mental health conditions and socioeconomic deprivation on unplanned admissions to hospital: a retrospective cohort study. Can Med Assoc J. 2013;185(5):E221-E8.

6. Bayliss E, Bayliss M, Ware J, Steiner J. Predicting declines in physical function in persons with multiple chronic medical conditions: what we can learn from the medical problem list. Health Qual Life Outcomes. 2004;2(1):47.

7. Fortin M, Bravo G, Hudon C, Lapointe L, Dubois MF, Almirall J. Psychological distress and multimorbidity in primary care. Ann Fam Med. 2006;4(5):417-22.

8. Gunn JM, Ayton DR, Densley K, Pallant JF, Chondros P, Herrman HE. The association between chronic illness, multimorbidity and depressive symptoms in an Australian primary care cohort. Soc Psychiatry Psychiatr Epidemiol. 2012;47(2):175-84.

9. Ryan A, Wallace E, O'Hara P, Smith SM. Multimorbidity and functional decline in community-dwelling adults: a systematic review. Health Qual Life Outcomes. 2015;13(168). https://doi.org/10.1186/s12955-doi:10. 1015-0355-9.

10. Barnett K, Mercer S, Norbury M, Watt G, Wyke S, Guthrie B. Epidemiology of multimorbidity and implications for health care, research, and medical education: a cross-sectional study. Lancet. 2012;380:37-43.

11. Mercer SW, Gunn J, Bower P, Wyke S, Guthrie B. Managing patients with mental and physical multimorbidity. BMJ. 2012;345:e5559.

12. Duerden M, Avery T, Payne R. Polypharmacy and medicines optimisation. http://www.kingsfundorguk/sites/files/kf/field/field_publication_file/ polypharmacy-and-medicines-optimisation-kingsfund-nov13pdf; 2015.

13. Guthrie B, et al. National Institute for Health and Care Excellence, NG56 Multimorbidity: clinical assessment and management. UK: National Institute for Health and Care Excellence (NICE); 2016.

14. May CR, Eton DT, Boehmer K, et al. Rethinking the patient: using Burden of Treatment Theory to understand the changing dynamics of illness. BMC Health Serv Res. 2014;14(1):281.

15. Wallace E, Salisbury C, Guthrie B, Lewis C, Fahey T, Smith SM. Managing patients with multimorbidity in primary care. BMJ. 2015;350:h176-h.

16. Muth C, Blom JW, et al. Evidence supporting the best clinical management of patients with multimorbidity and polypharmacy: a systematic guideline review and expert consensus. J Intern Med. 2018. https://doi. org/10.1111/joim.12842.

17. Smith SM, Wallace E, O'Dowd T, Fortin M. Interventions for improving outcomes in patients with multimorbidity in primary care and community settings. Cochrane Database Syst Rev. 2021;(1):CD006560. https://doi.org/ 10.1002/14651858.CD006560.pub4.

18. Almirall J, Fortin M. The coexistence of terms to describe the presence of multiple concurrent diseases. J Comorb. 2013;3:4-9.

19. Page MJ, McKenzie JE, Bossuyt PM, Boutron I, Hoffman TC, Mulrow CD, et al. The PRISMA 2020 statement: an updated guideline for reporting systematic review. Syst Rev. 2021;10:89.

20. Cochrane Effective P, Organisation of C. EPOC Resources for review authors, 2017. 2017. epoccochraneorg/resources/epoc-resources-reviewauthors (accessed 08 May 2020).

21. World Health Organization. Innovative care for chronic conditions: building blocks for action: global report. Geneva: Global Report; 2002.

22. Valderas J, Mercer S, Fortin M. Research on patients with multiple health conditions: different constructs, different views, one voice'. J Comorb. 2011:1-3. https://doi.org/10.15256/joc.2011.1.11. 
23. Vaneslow N, Donaldson M, Yordy K. A new definition of primary care. J Am Med Assoc. 1995;272(3):192.

24. Hoffmann TC, Glasziou PP, Boutron I, et al. Better reporting of interventions: template for intervention description and replication (TIDieR) checklist and guide. BMJ. 2014;348:g1687.

25. Guyatt GH, Oxman AD, Kunz R, Vist GE, Falck-Ytter Y, Schünemann HJ. GRADE Working Group. Rating quality of evidence and strength of recommendations: what is "quality of evidence" and why is it important to clinicians? BMJ. 2008:336(7651):995-8.

26. Smith Susan M, Wallace Emma, Salisbury Chris, Sasseville Maxime, Bayliss Elizabeth, Fortin Martin. A Core Outcome Set for Multimorbidity Research (COSmm). Ann Fam Med 2018; 16(2): 132-138.

27. Contant E, Loignon C, Bouhali T, Almirall J, Fortin M. A multidisciplinary self-management intervention among patients with multimorbidity and the impact of socioeconomic factors on results. BMC Fam Pract. 2019;20(1):53.

28. Eakin EGB, Bull SS, Riley KM, Reeves MM, McLaghlin M, Gutierrez S. Resources for health: a primary-care-based diet and physical activity intervention targeting urban Latinos with multiple chronic conditions. Health Psychol. 2007;26(4):392-400.

29. Garvey J, Connolly D, Boland F, Smith SM. OPTIMAL, an occupational therapy led self-management support programme for people with multimorbidity in primary care: a randomized controlled trial. BMC Fam Pract. 2015;16:59

30. Gonzalez-Ortega M, Gene-Badia J, Kostov B, Garcia-Valdecasas V, Perez-Martin C. Randomized trial to reduce emergency visits or hospital admissions using telephone coaching to complex patients. Fam Pract. 2017;34(2):219-26.

31. Hochhalter AK, Song J, Rush J, Sklar L, Stevens A. Making the most of your healthcare intervention for older adults with multiple chronic illnesses. Patient Educ Couns. 2010:81(2):207-13.

32. Krska J, Cromarty JA, Arris F, et al. Pharmacist-led medication review in patients over 65: a randomized controlled trial in primary care. Age Ageing. 2001;30(3):205-11.

33. O'Toole L, Connolly D, Boland F, Smith SM. OPTIMAL: enhancing selfmanagement of multimorbidity in primary care. Br J Gen Pract. 2020; in press.

34. Reed RL, Roeger L, Howard S, et al. A self-management support program for older Australians with multiple chronic conditions: a randomised controlled trial. Med J Aust. 2018;208(2):69-74.

35. Boult C, Reider L, Frey K, et al. Early effects of "Guided Care" on the quality of healthcare for multimorbid older persons: a cluster randomized controlled trial. J Gerontol. 2008;63(3):321-7.

36. Jager C, Freund T, Steinhauser J, et al. Impact of a tailored program on the implementation of evidence-based recommendations for multimorbid patients with polypharmacy in primary care practices-results of a clusterrandomized controlled trial. Implementation Sci. 2017;12(1):8.

37. Koberlein-Neu J, Mennemann H, Hamacher S, et al. Interprofessional medication management in patients with multiple morbidities. Dtsch Arzteblatt Int. 2016;113(44):741-8.

38. Mercer SW, Fitzpatrick B, Guthrie B, et al. The CARE Plus study - a wholesystem intervention to improve quality of life of primary care patients with multimorbidity in areas of high socioeconomic deprivation: exploratory cluster randomised controlled trial and cost-utility analysis. BMC Med. 2016;14(1):88

39. Muth C, Uhlmann L, Haefeli WE, et al. Effectiveness of a complex intervention on Prioritising Multimedication in Multimorbidity (PRIMUM) in primary care: results of a pragmatic cluster randomised controlled trial. BMJ Open. 2018;8(2):e017740-e.
40. Salisbury C, Man MS, Bower P, et al. Management of multimorbidity using a patient-centred care model: a pragmatic cluster-randomised trial of the 3D approach. Lancet. 2018;392(10141):41-50.

41. Schäfer I, Kaduszkiewicz H, Mellert C, et al. Narrative medicine-based intervention in primary care to reduce polypharmacy: results from the cluster-randomised controlled trial MultiCare AGENDA. BMJ Open. 2018:8:e017653-e.

42. Sommers LS, Marton KI, Barbaccia JC, Randolph J. Physician, nurse and social worker collaboration in primary care for chronically ill seniors. Arch Intern Med. 2000;160(12):1825-33.

43. Foster G, Taylor SJ, Eldridge SE, Ramsay J, Griffiths CJ. Self-management education programmes by lay leaders for people with chronic conditions. Cochrane Database Syst Rev. 2007;(4):CD005108. https://doi.org/10.1002/ 14651858.CD005108.pub2.

44. Dowrick C. Patient-centred care for multimorbidity: an end in itself? Lancet. 2018;392(10141):4-5.

45. Nieuwlaat R, Wilczynski N, Navarro T, Hobson N, Jeffery R, Keepanasseril A, Agoritsas T, Mistry N, lorio A, Jack S, Sivaramalingam B, Iserman E, Mustafa RA, Jedraszewski D, Cotoi C, Haynes RB. Interventions for enhancing medication adherence. Cochrane Database Syst Rev. 2014;2014(11):CD000011.

46. Challis D, Hughes J. Intensive care/case management, Expert Briefing Paper 1. Manchester: Personal Social Services Research Unit. 2014. http:// sites.nursing.manchester.ac.uk/pssru/research/nihrsscr/productsandtool kits/IntensiveCaseManagement.pdf.

47. Sinnott C, Mc Hugh S, Browne J, et al.GPs' perspectives on the management of patients with multimorbidity: systematic review and synthesis of qualitative research. BMJ Open 2013;3:e003610. https://doi.org/10.1136/ bmjopen-2013-003610.

48. Noël PH, Parchman ML, Williams JW Jr, Cornell JE, Shuko L, Zeber JE, Kazis $L E$, Lee AF, Pugh JA. The challenges of multimorbidity from the patient perspective. J Gen Intern Med. 2007;22 Suppl 3(Suppl 3):419-24. https:// doi.org/10.1007/s11606-007-0308-z.

49. Higgins J, Thomas J, Chandler J, et al. Cochrane Handbook for Systematic Reviews of Interventions version 6.1. Cochrane Database Syst Rev. 2020; Available from www.training.cochrane.org/handbook.

50. The IRCMO database. Available from https://www.usherbrooke.ca/crmcs $\mathrm{pl} /$ fileadmin/sites/crmcspl/documents/Publications_on_multimorbidity_ 01.pdf.

51. Prados-Torres A, Cura-Gonzalez ID, Prados-Torres JD, et al. MULTIPAP study: improving healthcare for patients with multimorbidity. Br J Gen Pract. 2020;70(suppl 1). https://doi.org/10.3399/bjgp20X711257.

52. Fisher K, Markle-Reid M, Ploeg J, et al. Self-management program versus usual care for community-dwelling older adults with multimorbidity: a pragmatic randomized controlled trial in Ontario, Canada. J Comorb. 2020;10:2235042X20963390. https://doi.org/10.1177/2235042X20963390.

53. Fortin M, Dionne J, Pinho G, Gignac J, Almirall J, Lapointe L. Randomized clinical trials: do they have external validity for patients with multiple comorbidities? Ann Fam Med. 2006;4(2):104-8.

54. Smith SM, Bayliss E, Mercer S, et al. How to design and evaluate interventions to improve outcomes for patients with multimorbidity. J Comorb. 2013;3(1):10-7.

\section{Publisher's Note}

Springer Nature remains neutral with regard to jurisdictional claims in published maps and institutional affiliations. 